\title{
TRAPACEANDO A LÍNGUA NO GOVERNO MÉDICI: UM ESTUDO SOBRE O IMAGINÁRIO DE LÍNGUA PELO JORNAL O PASQUIM*
}

\author{
Carme Regina Schons** \\ Cinara Sabadin Dagneze***
}

Resumo: O estudo reflete sobre o modo como as relações entre poder e força de resistência atuam na construção de um imaginário que agrega novos sentidos à língua. Considerando que o estudo da língua é ideológico, neste caso uma questão política, e que mudanças ocorrem, determinadas pelas leis e práticas sociais, são aqui analisados discursos de jornalistas publicados no jornal O Pasquim (1969 e 1970). Por se tratar de um jornal de oposição ao governo ditatorial, partimos da indagação: Que efeitos tais discursos teriam produzido, uma vez que se contrapunbam às práticas do governo militar utilizando-se do humor? Por meio de uma escrita simbólica, o humor trapaceia e perpassa a estrutura da lingua trabalhada em manuais de redação da imprensa brasileira no governo Médici. O texto jornalístico, mesmo resultando da prática de uma escrita especializada, institucionalizada em manuais de redação, pode ser pensado como espaço de resistências, equivocos e subjetividades.

Palavras-chave: Imprensa brasileira. Humor. Resistência.

\section{INTRODUÇÃO}

Estudar relações entre poder e forças de resistência, nos vários efeitos sobre as práticas identitárias das sociedades, e como tais relações atuam na construção de um imaginário sobre homem/língua, é o centro deste trabalho. Antes de discorrer sobre essas questões, gostaríamos de explicar o título deste artigo - "Trapaceando a língua no governo

\footnotetext{
* Uma primeira versão dessa reflexão foi apresentada em sessão de comunicação oral no "VIII Encontro do Centro de Estudos Linguísticos do Sul - Celsul", na Universidade Federal do Rio Grande do Sul, realizado de 29 a 31 de outubro de 2008, Porto Alegre. Posteriormente, apresentada no "II Simelp - Simpósio Internacional de Estudos de Língua Portuguesa", na Universidade de Évora, realizado de 6 a 11 de outubro de 2009, Portugal.

** Professora e pesquisadora do Curso de Letras e do Programa de Pós-Graduação em Letras da Universidade de Passo Fundo, mestre e doutora em Teorias do Texto e Discurso pela UFRGS. Email: carme regina@hotmail.com

*** Mestre em Letras, Estudos Linguísticos, pela Universidade de Passo Fundo (UPF). Email: cinara@upf.br
} 
Médici". Quando elaboramos a proposta, tínhamos em mente o conceito de língua proposto na obra de Gadet e Pêcheux (1981) La langue introuvable ${ }^{1}$. Ocorrem condições específicas de produção, que são constitutivas de identidades linguísticas e de sujeitos, no momento em que surge o jornal $O$ Pasquim. Destacamos a relação existente entre homem, língua e história, repassada pela censura como fato de linguagem - há recusa de submissão a ela - como forma de silêncio, conforme definida por Orlandi (1995).

A busca por aquilo que toca o (im)possível da língua - o discurso, o sujeito, a história - foi o impulso inicial que desencadeou este artigo. Estudar um imaginário que agrega outros sentidos à língua, construído nos discursos jornalísticos publicados na imprensa alternativa em plena ditadura militar, significa trazer à tona questões que não só recuperam uma memória de fatos que romperam com padrões no país, mas permitem discutir políticas de língua relativas à língua concebida pelo Estado.

A questão que orienta a organização do corpus proposto para analisar o discurso jornalístico d'O Pasquim no governo Médici permite observar duas posições sobre a abordagem da língua: a autorizada pelo Estado e a não autorizada por ele. E possível adiantar que a forte repressão imposta pela ditadura militar jogou por terra qualquer possibilidade de diálogo com a sociedade civil, produziu silenciamentos, esvaziou sindicatos, partidos, movimentos sociais, imprensa. No entanto, o jornalismo de oposição fez emergir, em vozes dissonantes, as fronteiras, os espaços flutuantes da língua e suas contradições. Desse modo, O Pasquim passa a viabilizar o estudo de peculiaridades de uma língua que transgride e que "falha", a ponto de pôr em xeque a todo o momento o sistema e a estrutura permitida pelos censores. Isso porque fez prevalecer aquilo que se poderia chamar "o próprio da língua", o que a toca mais de perto: o simbólico.

Para falar desse simbólico que tange as fronteiras do real da língua e da história e abala o princípio da univocidade, apoiamo-nos em Gadet e Pêcheux ([1981] 2004), para os quais

\footnotetext{
${ }^{1}$ Nessa obra de Gadet e Pêcheux - traduzida no Brasil por Bethania Mariani e Maria Elizabeth Chaves de Mello (2004) com o título de $A$ lingua inatingivel - encontramos uma discussão sobre os limites e as transgressões da língua no cenário histórico do século XX.
} 
[...] o que afeta o princípio da unicidade na língua não é localizável: o equívoco aparece como o ponto em que o impossível (linguístico) se une com a contradição (histórica); o ponto em que a língua toca à história. A irrupção do equívoco afeta o real da história, todo processo revolucionário afeta também o espaço da língua (p. 64).

A citação acima permite recuperar um conceito produtivo para a nossa reflexão, isto é, o conceito de equívoco como construtivo do processo discursivo, que também tem a ver com as questões relativas ao silêncio local, ou seja, com a proibição de determinados dizeres, o que não deixa de ser um instrumento de violência. Segundo Orlandi (1995, p. 71), o silêncio é a condição de significação e há uma incompletude constitutiva da linguagem quanto ao sentido e ao sujeito. "Quanto mais se diz, mais o silêncio se instala, mais os sentidos se tornam possíveis e mais se tem a dizer" (ORLANDI, 1995, p. 71).

Um jornal que modifica a linguagem jornalística, pois reproduz na linguagem escrita a linguagem oral, que se utiliza de palavrões que surgem disfarçados de neologismos, que cria novas condições de escrita, com novos termos, que podem ser usados jornalisticamente, pode (re)velar o que deve ser silenciado. Expressões do tipo pô, putsgrila, paca, sifu, top-top, sacumé, entre outras, tornam presente a "iminência do nãodito que se pode dizer" (ORLANDI, 1995, p. 72), uma vez que as proibições linguísticas também são formas de representação e vêm determinadas pelas relações sociais.

Vale lembrar que os interesses da imprensa alternativa iam além da resistência. $\mathrm{Na}$ época, tal imprensa procurava inúmeros caminhos de atuação no campo da defesa da ordem democrática e mostrava constante preocupação em denunciar tanto o crescente endividamento externo do Brasil quanto o agravamento das tensões sociais. A articulação da imprensa de oposição contra as forças repressivas não só leva jornalistas e intelectuais a criar espaços alternativos para a grande imprensa e para a universidade - haja vista 14 de março de 1967, depois de entrar em vigor a Lei de Imprensa, sancionada pelo presidente Castelo Branco um mês 
antes de concluir seu mandato - como também torna visíveis os diferentes silenciamentos que atravessam as palavras.

A questão de saber sobre essas transgressões e silenciamentos, no presente estudo, vem sustentada pelo humor ao revelar que podemos fazer malabarismos com a língua. O silêncio local, a censura, as restrições impostas podem levar a descobrir outras variações no modo de dizer, já que toda língua tem suas variantes, de acordo com as situações sociais pelas quais passa cada falante. No âmbito deste trabalho, propomo-nos rever o modo de $O$ Pasquim escrever.

\section{COMENTÁRIO: FUNDAÇÃO DO IMAGINÁRIO DE LÍNGUA NO ESPAÇO DA SUBVERSÃO}

Quando falamos em discurso, não podemos nos esquecer de que há uma relação necessária entre o discurso proferido e o lugar onde ele é enunciado (ou para quem ele é proferido). Tal relação nos impossibilita analisá-lo como se estivéssemos analisando um dizer apenas. É preciso referi-lo ao conjunto de discursos possíveis, a partir de um estado definido de condições de produção e de posições-sujeito. E a língua, enquanto sistema e materialidade dos discursos, presta-se às transformações de sentido dos dizeres das lutas de classe.

O discurso tomado na sua própria ordem, realizando-se na língua, na ordem do enunciável ${ }^{2}$, movimenta as fronteiras, os espaços discursivos; por isso, as transgressões na língua tornam-se inevitáveis. Conforme Gadet e Pêcheux (2004), "o real da língua se inscreve dentro da disjuntiva principal entre a noção de uma ordem própria, imanente à estrutura de seus efeitos, e a de uma ordem exterior que se revele a uma dominação que há de se conservar, restabelecer ou demolir ou aniquilar". O político na linguagem, portanto, supõe a sua dimensão material e a sua dimensão simbólica. Como nosso desafio está justamente em pensar a língua nacional não só em sua materialidade linguística, mas também no real da sua história, recuperamos, de forma breve, alguns efeitos que começaram a surgir em $O$ Pasquim.

${ }^{2}$ Ao enunciável corresponde a materialidade linguística, e à historicidade, a materialidade histórica.

SCHONS; DAGNEZE - Trapaceando a língua... 
Para refletir sobre as forças políticas que causaram os efeitos produzidos pelas formações imaginárias, que são importantes no processo de instituição dos sentidos desatados pelo $O$ Pasquim, transcrevemos a Figura 1 tal como se apresenta na capa da primeira edição do jornal, editado em junho de 1969. Observamos que as determinações amigos/inimigos configuram uma oposição semântica que aponta para o lugar institucionalizado de dois grupos na esfera social.

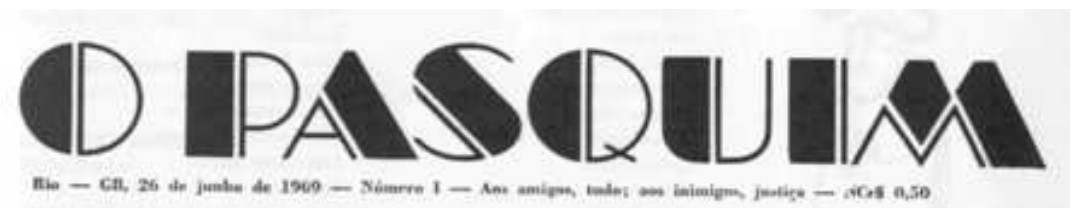

Figura 1 - Capa da primeira edição de O Pasquim

Notamos que, na sua formulação primeira, o comentário "Aos amigos, tudo; aos inimigos, justiça" é fundante de uma relação disjunta de lugares sociais, de posicionamentos, de premiação e sanção, os quais funcionam como referência ao imaginário constitutivo da imprensa brasileira e do País.

Essa determinação histórico-ideológica é fundamental para o efeito de realidade que se produz num discurso, para a constituição dos sentidos e para a configuração de lugares para o sujeito. De acordo com Orlandi (1993, p.7), “não há controle 'pessoal' ou 'coletivo' dos processos e da história de que sujeitos e sentidos participam. O que há é a aparência de controle e de certeza dos sentidos porque as práticas sócio-históricas são regidas pelo imaginário, que é político".

$\mathrm{Na}$ Figura 1, em "Aos amigos, tudo; aos inimigos, justiça" a elipse do verbo chama a atenção para a ausência (ou acobertamento) de ações em relação às determinações "amigos/inimigos". Ocorre na estrutura a abertura de um espaço a ser preenchido: de um lado, por verbos que recuperam o sentido de doação, de entrega e de premiação; de outro, por verbos que julgam ações de opositores.

Desse modo, na Figura 1, o comentário (em forma de legenda do nome do jornal) não só acresce informações a respeito da posição 
ideológica do jornal, como possibilita a identificação de, pelo menos, duas posições-sujeito.

Na posição-sujeito 1 (PS1), há o processo de identificação com a forma-sujeito da formação discursiva jornalística d'O Pasquim (FDJP); na posição-sujeito 2 , há a desidentificação com a forma-sujeito da formação discursiva estatal (FDE), entendida aqui como toda voz atrelada aos mecanismos de controle, às ações de punição dos representantes do Estado, aos censores, à imprensa oficial.

Por se tratar de um enunciado de abertura da primeira edição d'O Pasquim, a inserção do comentário logo após a designação do jornal rompe com a estrutura e cria um intervalo que, semanticamente, virá a ser preenchido pelo leitor. Assim, O Pasquim torna-se fundante de uma nova linha discursiva a ser adotada pelo jornalismo. Daí em diante, poderiam ser publicadas as mesmas palavras e expressões, ou os mesmos comentários que fossem representativos dessa linha ideológica transgressiva, na qual o jornalista, aderido ao sistema de língua, podia se manifestar contra o sistema social, contra uma política com a qual não concordava, mas que era, até então, obrigado a aceitar.

Ainda, é possível afirmar que a equipe de redatores d'O Pasquim desenhava e escrevia de maneira muito pessoal, irreverente. O tom de "molecagem" vem fundar novos sentidos, novas regras, no jogo com a língua na atividade escrita. Observamos na Figura 1, conforme explicaremos no decorrer deste texto, a utilização do comentário como crítica política no momento em que a imprensa oficial estava (e devia permanecer) calada. O comentário constitui uma regularidade em $O$ Pasquim e funciona como espaço de subjetividades, que marca, de um lado, a ordem institucional e, de outro, a subversão, que rompe com as regras do jornalismo, do sistema estabelecido: a da subversão. $\mathrm{O}$ comentário, desse modo, é constitutivo de memória e faz emergir o silenciado, o proibido, o ainda não pensado na estrutura da língua.

Ao se delimitarem esses espaços enunciativos, emerge um posicionamento de crítica e resistência diante da censura prévia e da ação dos censores. O efeito metafórico do enunciado Aos amigos, tudo; aos inimigos, justiça comporta, na estrutura da língua, o que acreditamos ser a blindagem feita pelo O Pasquim dos sentidos delimitados/impostos pelo sistema. Confunde-se o leitor (inimigo), que não sabe ao certo quem 
são esses amigos/inimigos nem se tais definições são em relação aos pasquinianos ou em relação ao próprio governo e seus filiados.

O efeito do comentário é o de um discurso que produz uma novidade; é constitutivo de identidades que são atravessadas por outras, presentes na história. Assim, a eficácia metafórica concretiza-se pelo comentário, que faz emergir as contradições, as vozes dissonantes, a subversão. Por uma série de substituições ligadas à similaridade tudo e justiça, o espaço criado no comentário assegura para o sujeito o sentido do objeto que ousa resistir e se insubordinar e se constitui em (e contra) um avesso constante do discurso oficial, fazendo emergir a falta de sentido que esse sujeito não suporta.

Segundo Mariani (1993, p. 35), "os mecanismos de controle da Igreja e do Estado forçam o apagamento do sujeito que está narrando, relatando, escrevendo a notícia". No entanto, o que ocorre na Figura 1 é a simulação de apagamento exercida por um sujeito que, mais do que nunca, faz prevalecer o seu jeito de escrever, já que se utiliza de um comentário para produzir efeito de evidência, mas que funciona como advertência, subversão. Em virtude disso, a relação entre o discurso proferido e o lugar onde é enunciado (ou para quem é proferido) simula um único discurso no qual não há, aparentemente, vozes dissonantes, uma vez que é referido ao conjunto de discursos possíveis, a partir de um estado definido de condições de produção, no qual a língua, enquanto materialidade, sofre transformações de sentido.

O discurso, produzido materialmente pela língua, não pode ser pensado senão por uma dupla materialidade - linguística e histórica -, já que "é na estrutura que se fixa o dizer e o acontecimento, que irrompe como um elemento que, ao mesmo tempo, desestrutura e reorganiza esse universo discursivo" (DE NARDI, 2009, p. 67). Com o exemplo não podemos deixar de rever as noções de sistema e de acontecimento formuladas por Pêcheux (1990) na obra Estrutura ou acontecimento. Para o autor, para o qual o sistema da língua - como um conjunto das relações que se mantêm - se transforma, há uma regularidade. No comentário presente no discurso pasquiniano, que para além do sentido se encaminha em direção ao subvertido da estrutura da língua na/pela historicidade, dissimula-se uma simetria que comporte o equívoco. $\mathrm{O}$ paradoxo da língua, com a roupagem do humor, atinge a ordem das regras. 
Foucault, na obra $A$ ordem do discurso, discute os procedimentos de controle do discurso. Ele observa o desnivelamento entre os discursos (aqueles de base e os simples comentários) e, no desnivelamento, o funcionamento do comentário.

[...] o fato de o texto primeiro pairar acima, sua permanência, seu estatuto de discurso sempre reatualizável, o sentido múltiplo ou oculto de que passa por ser detentor [...] tudo isso funda uma possibilidade aberta de falar. Mas, por outro lado, o comentário não tem outro papel [...] senão o de dizer enfim o que estava articulado silenciosamente no texto primeiro. Deve [...] dizer pela primeira vez aquilo que, entretanto, já havia sido dito, e repetir incansavelmente aquilo que, no entanto, não havia jamais sido dito (FOUCAULT, 1996, p. 25).

O comentário aparece na dinâmica da repetição, visto que o novo não está no que é dito, mas no retorno ao dizer, no acontecimento de sua volta. É preciso restituir ao discurso o seu caráter de acontecimento, diz Foucault. $\mathrm{O}$ autor entende que o discurso é uma violência que fazemos às coisas, como uma prática que lhe impomos e na qual os acontecimentos do discurso encontram o princípio de sua regularidade. Para analisar o discurso é preciso pensar o acontecimento, não a criação; pensar as séries, não a unidade; pensar a regularidade, não a originalidade; pensar as condições de possibilidade, não a significação.

A análise da Figura 1 mostra que toda produção de discurso, mesmo que controlada, selecionada, organizada e redistribuída por um certo número de procedimentos, que têm por função conjurar seus poderes e perigos, gera seus efeitos, ou seja, o discurso não pode se esquivar da "pesada e temível" materialidade histórica.

\section{O (IM)POSSÍVEL, O PROIBIDO NA/PELA LÍNGUA}

Feita essa breve exposição sobre o comentário, que será tratado aqui como estrutura e acontecimento, e o que implica na conceituação de língua, objetivamos tratar do político na língua, uma vez que na análise do corpus precisamos nos apoiar no político para poder discutir o 
(im)possível e o proibido na/pela língua, cujas transformações, sejam determinadas pela lei, sejam pelas práticas sociais, colocam em evidência os efeitos ideológicos. Os discursos de jornalistas publicados em edições d'O Pasquim entre os anos 69 e 70, via formações imaginárias, levam-nos a um contato com a realidade histórica e ideológica de práticas sociais que atravessam e constituem tal realidade, ou seja, num regime totalitário, no qual o humor é considerado "fora da lei". O Pasquim (des)constrói a imagem do discurso jornalístico como um discurso que se supõe isento/neutro de julgamentos e subjetivações.

Tal desconstrução, subversão, é entendida aqui como o político da linguagem e o impossível - o proibido enquanto atividade política -, presentes na língua e na história daquilo que é dito e também daquilo que não é dito. O interditado na língua é constitutivo de "coisas-a-saber" (PÊCHEUX, 1990, p. 34). Coisas essas, de acordo com o referido autor, que se apresentam regidas pela lei do impossível de ser dito, mas impossível de não fazer parte do dito. Há a emergência de um acontecimento na estrutura da língua que suporta também o inconsciente da língua, a simulação da completude, o equívoco e, ainda, o humor "fora da lei".

Tomamos, na sequência de nossa discussão, a Figura 2:

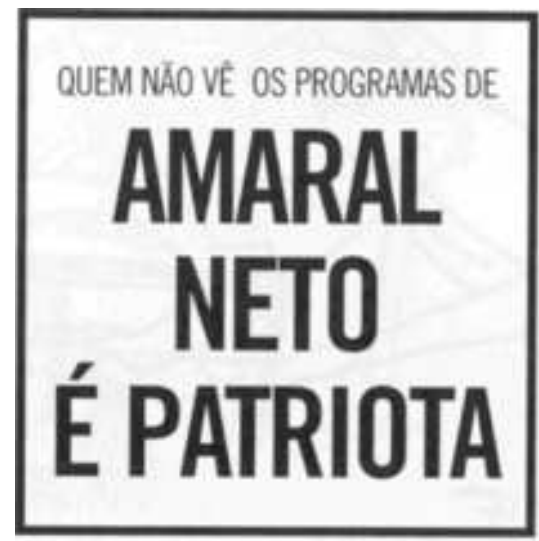

Figura 2 - Texto de O Pasquim 
O dizer, em caixa alta, afirma que Amaral Neto é patriota num primeiro momento da leitura. Quando o leitor se aproxima do texto, porém, percebe a falácia, pois é quem não vê os programas de Amaral Neto que é patriota.

Numa perspectiva enunciativo-discursiva, do modo como é tratada por Guimarães (2002, p. 21), a designação do nome próprio Amaral Neto, ${ }^{3}$ segundo o autor, "é uma construção com determinação". Isso nos permite dizer que há, enrustidos na designação cuja determinação é patriota, dois sujeitos falados pelo O Pasquim: o patriota (aquele que não vê os programas de Amaral Neto) e o não patriota (o próprio Amaral Neto e os que assistem aos programas de Amaral Neto). O nome próprio funciona, portanto, como um processo de identificação social do nomeado.

A duplicidade presente na designação/determinação Amaral Neto/patriota inscreve o simbólico no real da língua e no real da história. Não só ocorre uma memória sobre o que se dizia e o que era feito nos programas de Amaral Neto e que o qualificam como antipatriótico, como também se produz efeito avaliativo da informação silenciada, que deve ser lembrada. Em consequência disso, a classe de brasileiros fica dividida em dois grupos distintos: os patriotas e os não patriotas, resultantes da ação de ver/não ver os programas de Amaral Neto.

O conflito gerado pela estrutura do enunciado, entre texto (caixa alta) e comentário (no fundo), produz efeito de fragmentação. Há, inicialmente, uma posição-sujeito que reconhece a existência de Amaral Neto como patriota; depois, surge outra posição-sujeito, que traz à tona a afirmativa verdadeira, visto que determina quem realmente é patriota: Quem não vê programas de Amaral Neto. O aparente efeito de unicidade produzido na indefinição determina que nem todos assistem aos programas; portanto, aqueles que não os veem são os patriotas. É a designação Amaral Neto que determina o lugar desses sujeitos na esfera social; mais precisamente, situa-os político-ideologicamente. A tensão entre essas duas perspectivas gerada pela ligação estar a serviço do

\footnotetext{
3 Amaral Neto atuou na Rede Globo, fundada em 1965. Considerado um jornalista polêmico, em 1969 criou um novo estilo de documentários na TV: o programa "Amaral Neto, o Repórter". Anos mais tarde, nas décadas de 1980 e 1990, passaria a dirigir o Centro de TV e cinema da Petrobrás.
} 
governo (Amaral Neto) e ser/estar no governo (instituição) desvela a subjetivação do jornalista, ou seja, a de desidentificação com os saberes da Formação Discursiva Estatal.

$\mathrm{O}$ indefinido quem funciona como um alerta na leitura a ser realizada pelo leitor d'O Pasquim. É justamente o indefinido que traz para a superfície outras determinações, como patriota ou não patriota, acomodados ao regime ou subversivos; enfim, o indefinido como sujeito do enunciado, no comentário, enfatiza as diferenças entre editores e jornalistas d'O Pasquim e os censores, com suas vozes disciplinadoras e homogeneizantes.

A alusão ao lugar de resistência a ser ocupado pelos brasileiros patriotas reforça as diferenças entre os adeptos do regime totalitário e os considerados subversivos. Por ser assim, o discurso pasquiniano inserese no fluxo de um imaginário brasileiro que se organiza pela negação presentificada no comentário.

$\mathrm{Na}$ estrutura do enunciado em forma de anúncio o enunciador esconde algo que é obrigado a dizer, mas que não quer dizer, ou seja, Amaral Neto é patriota. Observa-se que em O Pasquim, a autocensura ocorre no lugar da censura prévia. $\mathrm{O}$ ato de informar em $O$ Pasquim se constrói no dizer clandestino; está em desvelar o que a proibição impede que se diga. Encontra-se revelado o que deve ser silenciado no próprio comentário do enunciador. $\mathrm{O}$ efeito de negação não se dá apenas no intradiscurso - pela estrutura -; aparece na verticalização - pelo interdiscurso -, uma vez que se faz necessário afirmar o que não se quer dizer para emergir o silenciado, o proibido, isto é, aquilo que não deve nem pode ser falado.

Observamos que o sujeito desse enunciado (comentário) representa uma posição ideológica contrária à dos programas de Amaral Neto. No entanto, o rompimento dos sentidos naturalizados no intradiscurso dá-se somente no comentário - que funciona como estrutura e acontecimento. "Quem não vê os programas de" vem negar o afirmado em "Amaral Neto é patriota". Em decorrência disso, é possível afirmar que a estrutura do enunciado abre a possibilidade da instalação do equívoco em ser/não ser patriota; nela, o funcionamento dos processos discursivos produz efeito metafórico. Nessa mesma estrutura podemos perceber em que condições sócio-históricas o 
enunciado adquire espessura de acontecimento discursivo. Como em períodos de ditadura o cidadão não pode nem deve desobedecer, nem falar, nem resistir, é na/pela língua que se torna possível fazer/dizer. O que Amaral Neto produz como programa, na visão pasquiniana, é antipatriótico; por isso, deve ser denunciado, revelado, mesmo sob o risco de interdição. Perseguições e punições àqueles que burlassem as leis da censura no Brasil configuram os saberes cristalizados na memória brasileira sobre as práticas institucionalizadas durante a ditadura.

Vale lembrar que durante o período da ditadura militar, de modo geral, os representantes do governo e seus cúmplices preocupavam-se em disfarçar os delitos que ocorriam no governo, além da visível manipulação política. Para tal fim, utilizavam-se de um mecanismo de controle aparentemente inofensivo: a imprensa autorizada, que encobria a censura prévia. Esta representou, de modo velado, a preservação da aparente democracia e passou a consolidar lugar de oposição ante $O$ Pasquim.

Segundo historiadores, o jornalista Amaral Neto foi considerado um dos grandes maquiadores dos males da ditadura. O seu descaramento era tanto que chegou a receber de alguns o apelido de Amoral Nato. $\mathrm{Na}$ época, o jornalista tinha um programa pautado pelos militares para enaltecer as belezas do Brasil Grande. Amaral Neto foi o responsável por, entre outras "curiosidades", apresentar para o resto do País a pororoca, o encontro das águas do Amazonas com o mar. Conforme é possível observar nas Figuras 1 e 2, há no comentário um sentido velado sobre aquilo que não deve e não pode ser dito.

Tratar do (im)possível da língua, como fez a imprensa de resistência (O Pasquim), nas mais variadas formas (humor, silenciamentos, mudanças lexicográficas, metáforas, comentários), significa trazer para o rol de discussões o que estaria dentro/fora da língua. Mas qual o limite entre o dentro e o fora de uma língua?

Nossa intenção, no presente texto, não é abordar cada uma dessas questões, porque demandaria um longo espaço de investigação. Optamos por analisar, na próxima seção, o ponto de encontro entre o real da língua e o real da história e também refletir sobre o (im)possível, o proibido na/pela língua (o comentário). 


\section{CONSIDERAÇÕES EM ABERTO SOBRE OS ATOS PROIBIR, SUBVERTER E ANIQUILAR NO/PELO COMENTÁRIO}

As Figuras 3 e 4 são mais dois recortes de textos publicados em $O$ Pasquim que subvertem o dizer naturalizado na mídia oficial. Como ocorre nas Figuras 1 e 2, o comentário qualifica duplamente o dizer do texto destaque (em caixa alta), ou seja, é por meio do comentário que o sujeito-jornalista posiciona-se - enquanto sujeito responsável pelo dizer -, para rechaçar a ideologia dominante.

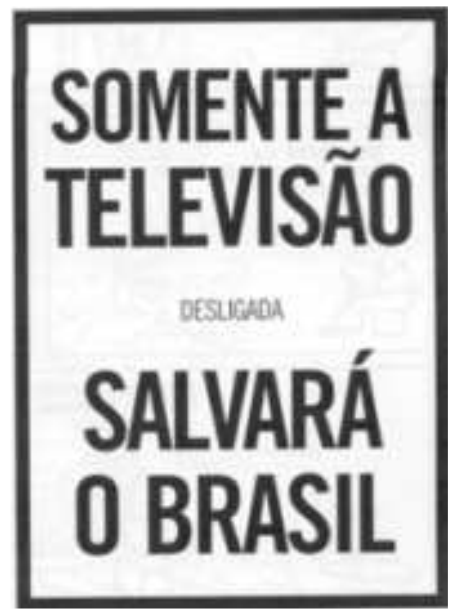

Figura 3 - Texto d'O Pasquim

Observamos, primeiramente, a forma integrada entre o enunciado do que se deve e pode dizer e o outro enunciado, do que não se deve e não se pode dizer. Vale lembrar, a determinação desligada da designação televisão produz um efeito de contradição e antagonismo entre os sujeitos falados pelo O Pasquim. (" $\mathrm{x}$ " só será " $\mathrm{x}$ ", se somente ocorrer " $y$ "). 
É pertinente salientar:

Nos jornais, a auto-censura passa a ser praticada como uma forma de defesa do dizer - um dizer que se restringe à idéia de informação. Em outras palavras, a noção de informação no jornalismo só pode ser avaliada como decorrência das leis que regulam a liberdade de imprensa. Sendo assim, informar/comunicar (na imprensa) é o resultado de um duplo controle: um controle exterior, vindo do Estado e do sistema jurídico por um lado e, por outro, um controle internalizado na própria atividade jornalística. (MARIANI, 1993, p. 35)

Vale entender, o poder totalitário interessa-se de tal maneira pela língua que quer dominá-la, reduzi-la a um instrumento de normalização do pensamento, porque ela não só representa a memória viva dos homens, mas lhes oferece possibilidades infinitas de resistência.

De acordo com o que observa Mariani na citação acima, é nas posições de classes, umas em conflito com as outras, que se pode entrever a relação das ideologias com o discurso, pois, diante da ameaça, o poder mobiliza-se para fazer desaparecer usos obscuros, apagando os pontos incompreensíveis e as zonas de incompreensão que põem em questionamento o controle do Estado e do sistema jurídico. Como formulam Gadet e Pêcheux (2004, p. 95): "No espaço língua, a busca impossível da unidade imaginária é paga ao alto preço da dupla linguagem da dominação".

Se as ideologias têm uma "existência material", o discursivo será considerado como um desses espaços materiais. O que pode e deve ser dito (dentro de suas variadas articulações) é feito a partir de uma dada posição, numa dada conjuntura, ou seja, numa dada relação de lugares ${ }^{4}$

\footnotetext{
4 Vale lembrar que, a partir de Bakhtin (1929) e, posteriormente, com Foucault (1995), a materialidade da língua e a materialidade do discurso já são concebidas em ordens distintas. Para este último, as coisas, os fatos, as palavras, extraordinariamente, exprimem uma história que se desenha à medida que se constroem sentidos, isto é, não é a relação simétrica e transparente entre os termos da frase que caracteriza o discurso de "fazer sentido", "fazer falar". É, pois, no jogo enunciativo que permite que "se diga" que o enunciado supõe outros; que tem, em torno de si, "um campo de coexistências, efeitos de série e de sucessão, uma distribuição de funções e de papéis". (FOUCAULT, 1995, p. 114).
} 
no interior de um aparelho ideológico e inscrita numa relação de classes. Logo, o modo de conceber a língua provém de condições específicas, identificáveis a partir de nossas concepções teóricas e, sobretudo, do lugar que ocupamos dentro dessa relação de classes. Essa é uma das razões pelas quais as línguas são suscetíveis ao político.

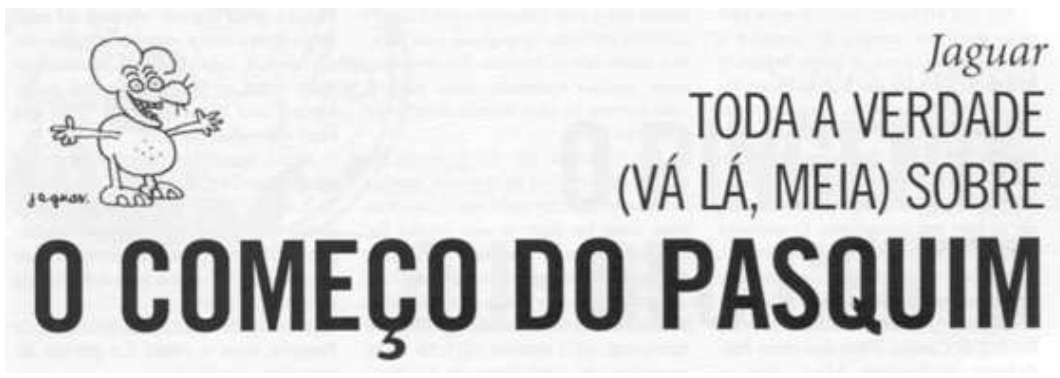

Figura 4 - Texto d'O Pasquim

Milner (1987), retomando algumas das formulações de Lacan, define o real da língua como o impossível. Para ele, o real está relacionado com aquilo que a língua tem de impossível, isto é, o impossível está ligado a alguma proibição, ao "foracluído" (expressão empregada por Gadet e Pêcheux, 2004, p.19).

$\mathrm{Na}$ figura 4, o retorno ao já dito como subversão da ordem, como negação, como reestruturação do dizer (não toda, mas meia verdade) produz deslocamentos, pois aquilo que retorna é imersão do novo no discurso, um furo numa estrutura já fixada pelo acontecimento e que passa a significar. O acontecimento aparece em Pêcheux (1990) como uma espécie de princípio de organização, já que pode ser trabalhado tanto no seu contexto de atualidade quanto num espaço de memória. Essa memória é que será reorganizada pelo acontecimento, que remete sempre a um conteúdo ao mesmo tempo imensamente transparente porque aparece como um efeito de evidência, um dizer que não poderia ser, naquele momento, senão aquele -, e profundamente opaco, porque carrega consigo uma série de práticas anteriores que possibilitaram a sua eclosão (ou tentaram impedir seu aparecimento). 
Conforme Pêcheux (1990), a denominação do acontecimento é anterior ao seu surgimento. É essa prática anterior, esse jogo de determinações, que lhe dá forma. É pela repetição que o enunciado se prende ao acontecimento. É o acontecimento também o responsável por levar a que um enunciado que surgiu em outro lugar, produzindo sentidos outros, seja deslocado, venha a se re-significar, desse modo, produzindo novos ecos. Isso ocorre, no entanto, sem que esse enunciado possa se libertar dos resquícios do lugar por ele já ocupado.

Quanto ao real da história, conforme Gadet e Pêcheux (2004), o materialismo histórico é o real contraditório. De acordo com a noção de real trabalhada por Pêcheux em Estrutura ou acontecimento, não se trata de um real logicamente estável, mas de "um real constitutivamente estranho à univocidade lógica, e um saber que não se transmite, não se aprende, não se ensina, e que, no entanto, existe produzindo efeitos" (PÊCHEUX, 1990, p. 43).

Pêcheux (1995), em Semântica e discurso, refere-se a domínios de saberes marxista-leninistas para mostrar que a prática discursiva é a forma como a prática política se materializa no domínio simbólico da linguagem. É, pois, no processo discursivo que se encontram inseridas as condições de observação da prática política. Desse ponto de vista teórico-metodológico, Pêcheux (1995, p. 206) nos mostra que a prática política é um espaço permanente de observação das relações contraditórias de reprodução e de transformação, uma vez que sua constituição ocorre no seio de contradições e de relações desiguais dentro da luta de classes.

Cabe dizer que Pêcheux não só procura o lugar (lugares) do sujeito, excluído da linguística estrutural, mas também mostra que o trabalho de interpretação é um contínuo processo de construção/desconstrução. É preciso entender tais pressupostos como objetivos de uma filosofia marxista. Para ele (1995, p. 207), a presença da forma-sujeito e sua condição de desdobramento em posições-sujeito heterogêneas nos permitem, ao mesmo tempo, tratar das relações de contradição e antagonismo no interior das formações discursivas e, entre elas, respectivamente, dos conjuntos de interesses conflitantes no interior de uma mesma formação discursiva, sempre tendo em vista a interlocução que nela se estabelece e que marca embate permanente entre o ideológico e o linguístico. 
Reportamo-nos ao pensamento marxista de que a autotransformação só existe na história, num processo global de transformação continuada. Em nosso trabalho, a proposta é pensar o discurso na sua ordem própria, distinta da materialidade da língua. Segundo orientação de Gadet e Pêcheux (2004, p. 37), "A questão da língua é, portanto, uma questão de Estado, com uma política de invasão, de absorção e de anulação das diferenças", que supõe a existência de uma ordem própria, imanente à estrutura de seus efeitos e a de uma ordem exterior que se remete a uma denominação histórica.

No intuito de estabelecer relações entre as áreas do conhecimento e de fundamentar as questões relativas à prática política, implicada aí a noção de processo discursivo, vale lembrar que, na perspectiva das ciências sociais, o princípio de contradição fundamenta os estudos do materialismo histórico e do materialismo dialético.

Pressupondo que tratar de contradição acarreta posturas teóricas diferentes, embasadas em teorias que são sustentadas em pressupostos teóricos diferentes, o analista de discurso entende a contradição como heterogeneidade discursiva, porque a heterogeneidade assinala

[...] as condições concretas de existência das contradições pelas quais a história se produz sob a repetição das memórias "estratégicas". Tal determinação também implica a construção dos meios de análise linguística e discursiva, e supõe uma reflexão sobre o que trabalha na e sob a gramática, à margem discursiva da língua. Não se trata, portanto, da reinvenção do mito antilinguístico da fala livre, bela selvagem que escapa às "regras". (PÊCHEUX, [1981] 2009, p. 25).

A articulação entre a linguística e a história pode ser vista como uma tendência de plausibilidade científica pela Análise do Discurso, não no sentido de interdisciplinaridade, mas no que toca às questões de linguagem pelo viés da política. Contudo, abordar esse ponto nos conduz a outros "continentes" e nos torna errantes em nossas buscas. É importante observar que o não-dito, o esquecido e o silenciado não devem se tornar barreiras nem fronteiras ao trabalho da interpretação.

Leandro Ferreira (2005), no artigo intitulado "A língua da análise do discurso: esse estranho objeto de desejo", ao discorrer sobre a obra 
La langue introuvable, de Gadet e Pêcheux, afirma que "a língua, assim como o discurso, não constituem uma estrutura fechada, homogênea, estável. Essa estrutura, esse todo representável que é a língua, comporta em si igualmente o não-todo, o não representável (o "introuvable")" (p. 217).

No caso do nosso corpus, que é constituído por discursos que foram publicados em um jornal de resistência no período em que era preciso driblar, trapacear a língua para desautorizar os sentidos cristalizados (estes por exigência do governo militar), o uso do humor torna-se exemplo vivo de que a língua está sujeita a inúmeras (des)construções, transgressões, subversões. Por meio de uma escrita simbólica, foi possível pôr em circulação determinados sentidos, perpassando a estrutura formal da língua, na qual é preciso deixar a historicidade trabalhar. Isso nos possibilita pensar a língua como espaço de resistências, de equívocos e de subjetividades.

\section{TECENDO ALGUMAS CONSIDERAÇÕES}

A subversão na/pela língua n' $O$ Pasquim não é semelhante à subversão política, embora língua e política sejam coexistentes. A subversão na/pela língua depende das condições de produção e do contexto político e ideológico, aliás, como qualquer funcionamento. A subversão na política, efeito ideológico, produz imaginário sobre língua, cidadão, lugar de trabalhador... A análise mostrou que as relações de poder e/ou as forças de resistência podem ser observadas no funcionamento da estrutura da língua dos discursos publicados em $O$ Pasquim, assim produzindo efeitos sobre..., imaginários sobre..., e é a isso que o verbo "trapaceando", tomado emprestado de Pêcheux e Gadet no título deste artigo, busca representar.

Convém mostrar que o imaginário sobre língua construído em $O$ Pasquim recupera, pelo interdiscurso, posições-sujeito heterogêneas e que os processos de memória produzem esquecimentos, antecipações e apontam para uma disputa de lugares/poder e política. Observa Orlandi (2002): o que funciona na memória discursiva, na identidade nacional, são as imagens construídas para nossa relação com a língua portuguesa, nossa "versão" brasileira dessa relação. 
Cabe ainda dizer que, quando tomamos as transformações da língua não apenas em seus aspectos cronológicos e consideramos a sua historicidade, é preciso considerar também o político e o simbólico.

Da mesma maneira é que vemos na construção da língua nacional um paralelo dessa relação, de tal modo que podemos dizer que na construção do imaginário social a história da constituição da língua nacional está estruturalmente ligada à constituição da forma histórica do sujeito sociopolítico, que se define assim na relação com a formação do país, da nação, do Estado. (ORLANDI, 2002, p.21).

Ainda, afirma Orlandi (2002, p. 24):

Essa heterogeneidade é tanto mais importante quanto sua ação é menos detectável, já que os processos históricos não são diretamente visíveis na língua. É assim que funcionam os objetos simbólicos em sua historicidade. No caso do português, podemos dizer, então, que são distintos sistemas simbólicos (o do Brasil e o de Portugal) com distintas histórias (linguísticas), mas aparentando a mesma materialidade empírica. Daí os equívocos. A observância da (mesma) materialidade empírica não deixa ver (desconhece) a distinta materialidade histórica.

No caso da análise do corpus - O Pasquim, jornal criado em julho de 1969 -, vimos que institucionalizou um espaço para que certas estruturas da língua pudessem funcionar como espaço de ironia, de contestação e de subversão. $O$ funcionamento dessas estruturas abriu espaço para o acontecimento político, pois foi via $O$ Pasquim que se produziu um imaginário sobre inimigos do governo, sobre subversivos, sobre antipatriotas; por isso, a censura ficou atenta e passou a "colaborar" com o jornal. A partir de 1972, O Pasquim passou a ser censurado em Brasília e qualquer palavra solta, ou nova, era censurada, porque, no olhar dos censores, podiam ser códigos ligados aos subversivos, a grupos de resistência. Espaço para os intelectuais? Se, para estes, restava-lhes apenas a espada da intransigência sobre suas cabeças, para os autores d'O Pasquim, a sobrevivência do jornal somente era possível "trapaceando" a própria língua. 


\section{REFERÊNCIAS}

DE NARDI, F. S. Entre a estrutura e o acontecimento: uma releitura de Pêcheux e Foucault em busca do sistema. In: SOUZA, P. de; GOMES, D. de O. (Orgs.). Foucault com outros nomes: lugares de enunciação. Ponta Grossa: Editora da Universidade Estadual de Ponta Grossa, 2009. p. 67-76.

FOUCAULT, M. A arqueologia do saber. 4. ed. Rio de Janeiro: Forense Universitária, 1995.

. (1970). A ordem do discurso. São Paulo: Edições Loyola, 1996.

GADET, F.; PÊCHEUX, M. (1981). A língua inatingível. Trad. Bethânia Mariani e Maria Elizabete Chaves de Mello. Campinas: Pontes, 2004.

GUIMARÃES, E. Semântica do acontecimento: um estudo enunciativo da designação. Campinas: Pontes, 2002.

LEANDRO FERREIRA, M. C. A língua da análise de discurso: esse estranho objeto de desejo. In: INDURSKY, F.; LEANDRO FERREIRA, M. C. (Orgs.).

Michel Pêcheux e a análise do discurso: uma relação de nunca acabar. São Carlos: Claraluz, 2005. p. 213 -218.

MARIANI, B. Os primórdios da imprensa no Brasil (ou: de como o discurso jornalístico constrói memória). In: ORLANDI, E.P. (Org.). Discurso fundador. Campinas, SP: Pontes, 1993.

MILNER, J.-C. O amor da língua. Trad. Angela Cristina Jesuino. Porto Alegre: Artes Médicas, 1987.

ORLANDI, E.P. Prefácio. In: SP: Pontes, 1993. p. 7-9. (Org.). Discurso fundador. Campinas,

ORLANDI, E.P. As formas do silêncio: no movimento dos sentidos. 3. ed. Campinas, São Paulo: Editora da Unicamp, 1995.

Língua e conhecimento linguístico: para uma história das ideias no Brasil. São Paulo: Cortez, 2002.

PÊCHEUX, M. (1983). O discurso: estrutura ou acontecimento. Trad. E. Orlandi. Campinas: Pontes, 1990.

Semântica e discurso: uma crítica à afirmação do óbvio. Campinas: UNICAMP, 1995.

O estranho espelho da análise de discurso (1981). In: COURTINE, J.J. Análise do discurso político: o discurso comunista endereçado aos cristãos. 
Tradução Bacharéis em Letras pela Universidade Federal do Rio Grande do Sul, no âmbito do Projeto "A tradução no Instituto de Letras: da teoria à prática".

São Carlos: EduFSCar, 2009.

\section{Referência das figuras:}

AUGUSTO, S.; JAGUAR (Orgs.). O melhor do Pasquim. In: O Pasquim. Rio de Janeiro: Ed. Desiderata, v. 1, 2006. (Antologia)

Recebido em 08/09/10. Aprovado em 05/04/11.

Title: "Cheating" the language in the Médici Government: A study on the language imaginary by the Newspaper O Pasquim

Authors: Carme Regina Schons; Cinara Sabadin Dagneze

Abstract: This study reflects on how the relations between Power and resisting forces act in the building of an imaginary that adds news meanings to language. Since language study is ideological, in this case a political issue, and that changes occur as determined by social laws and practices, here discourses by journalists that were published in the newspaper O Pasquim (1969 and 1970) are analyzed. As it was a newspaper, which opposed the dictatorial government, our initial question was: What effect such discourses would have produced, considering that it opposed the practices by the military government by means of humor? By using a symbolic writing, humor cheats and pervades the structure of the worked language in writing manuals used by the Brazilian press during the Médici government. At the same time, the journalistic text, even if resulting from a specialized writing practice, institutionalized by writing manuals, can be thought of as a space for resistance, mistakes and subjectivities.

Keywords: Brazilian press. Humor. Resistance.

Titulo: "Trampeando" la lengua en el gobierno Médici: un estudio sobre el imaginario de lengua por el periódico O Pasquim

Autores: Carme Regina Schons; Cinara Sabadin Dagneze

Resumen: El estudio reflexiona sobre el modo como las relaciones entre poder y fuerza de resistencia actuan en la construcción de un imaginario que agrega nuevos sentidos a la lengua. Considerando que el estudio de la lengua es ideológico, en este caso una cuestión política, y que cambios ocurren, determinadas por las leyes y prácticas sociales, son aqui analizados discursos de periodistas publicados en el periódico $O$ Pasquim (1969 y 1970). Por tratarse de un periódico de oposición al gobierno dictatorial, partimos de la indagación: ¿Qué efectos tales discursos habrían producido, una vez que se contraponian a las prácticas del gobierno militar utilizando el humor? Por medio de una escritura simbólica, el bumor trampea e impregna la estructura de la lengua trabajada en manuales de redacción de la prensa brasileña en el gobierno Médici. El texto periodístico, aun resultando de la práctica de una escritura especializada, institucionalizada en manuales de redacción, puede ser pensado como espacio de resistencias, equívocos y subjetividades.

Palabras-clave: Prensa brasileña. Humor. Resistencia.

Linguagem em (Dis)curso, Tubarão, SC, v. 11, n. 1, p. 37-57, jan./abr. 2011 